\title{
Genetic association analysis of TAP1 and TAP2 polymorphisms with aspirin exacerbated respiratory disease and its FEV1 decline
}

\author{
Jeong-Hyun Kim ${ }^{1}$, Byung-Lae Park ${ }^{2}$, Charisse Flerida A Pasaje ${ }^{1}$, Joon Seol Bae ${ }^{1}$, Jong Sook Park ${ }^{3}$, Sung \\ Woo Park ${ }^{3}$, Soo-Taek $\mathrm{Uh}^{3}$, Mi-Kyeong Kim ${ }^{4}$, Inseon S Choi ${ }^{5}$, Sang Heon $\mathrm{Cho}^{6}$, Byoung Whui Choi ${ }^{7}$, \\ Choon-Sik Park ${ }^{3}$ and Hyoung Doo Shin ${ }^{1,2}$
}

Aspirin exacerbated respiratory disease (AERD) induces bronchoconstriction in asthmatic patients characterized with a clinical condition of severe decline in forced expiratory volume in one second (FEV1) after ingestion of aspirin. Two genes consisting a heterodimer, transporter 1 and 2, ATP-binding cassette, sub-family $B$ (MDR/TAP) (TAP1 and TAP2) within the major histocompatibility complex (MHC) region, have been implicated in immunodeficiency and bronchiectasis development. To investigate the associations of TAP1 and TAP2 genetic polymorphisms with AERD and phenotypic FEV1 decline, a total of 43 common single-nucleotide polymorphisms (SNPs) including 12 SNPs of TAP1 and 31 SNPs of TAP2 were genotyped in 93 AERD patients and 96 aspirin-tolerant asthma controls. Interestingly, regression analysis revealed that polymorphisms and haplotypes of TAP2 were associated with FEV1 decline by aspirin provocation $(P=0.002-0.04)$, with about twofold decline rate of FEV1 in most of minor homozygotes compared with major homozygotes. In addition, nominal evidences of association between TAP2 and AERD development were observed $(P=0.02-0.04)$. However, TAP1 polymorphisms showed no relations to both AERD and FEV1 decline after aspirin challenge $(P>0.05)$. Although further functional evaluations and replications are required, our preliminary findings provide supporting information that variants of TAP2 might be predisposing factors for FEV1 decline-related symptoms.

Journal of Human Genetics (2011) 56, 652-659; doi:10.1038/jhg.2011.75; published online 28 July 2011

Keywords: aspirin exacerbated respiratory disease (AERD); haplotype; single-nucleotide polymorphism; TAP1; TAP2

\section{INTRODUCTION}

Aspirin exacerbated respiratory disease (AERD) is characterized by distinct clinical symptoms associated with severe bronchoconstriction after ingestion of non-steroidal anti-inflammatory drugs including aspirin. Estimates of AERD prevalence are about $0.6-2.5 \%$ in the general population and $10-20 \%$ in asthmatic patients. ${ }^{1,2}$ The disease often accompanies by other symptoms referred to aspirin triad, such as bronchial asthma and chronic rhinosinusitis with nasal polyps. ${ }^{2,3}$ Forced expiratory volume in one second (FEV1), as one of criteria for total lung capacity, can determine severe decline of lung function. Although comprehensive mechanisms have not been known, changes in the structure and function of the airways cause bronchospasms. Although pathophysiology of AERD has been closely linked to the overproduction of cysteinyl-leukotrienes (CysLTs), ${ }^{4}$ recent studies have also reported that genes on other pathways, such as the structural gene protocadherin-1 (PCDH1) and the transporter gene solute carrier family 6 (neurotransmitter transporter, betaine/GABA) member 12 (SLC6A12), could be involved in the development of aspirin hypersensitivity in asthmatics. ${ }^{5,6}$

Both transporter 1 and 2, ATP-binding cassette, sub-family B (MDR/ TAP) (TAP1 and TAP2), also referred as transporter associated with antigen processing, are located within the major histocompatibility complex (MHC) class II region of the leukocyte antigen (HLA) locus on human chromosome 6. TAP complex is a heterodimer consisted of two subunits encoded by TAP1 and TAP2. Mutations in either TAP1 or TAP2 have been found to impair the translocation of peptides from the cytosol into the endoplasmic reticulum. ${ }^{7}$ The TAP deficiency syndrome characterized by immunodeficiency usually shows recurrent

${ }^{1}$ Department of Life Science, Sogang University, Seoul, Republic of Korea; ${ }^{2}$ Department of Genetic Epidemiology, SNP Genetics, Inc, Seoul, Republic of Korea; ${ }^{3}$ Division of Allergy and Respiratory Medicine, Soonchunhyang University Bucheon Hospital, Bucheon, Republic of Korea; ${ }^{4}$ Division of Internal Medicine, Chungbuk National University, Cheongju, Republic of Korea; ${ }^{5}$ Department of Allergy, Chonnam National University, Gwangju, Republic of Korea; ${ }^{6}$ Department of Internal Medicine and Institute of Allergy and Clinical Immunology, Seoul National University, Seoul, Republic of Korea and ${ }^{7}$ Department of Internal Medicine, Chung-Ang University Yongsan Hospital, Seoul, Republic of Korea Correspondence: Dr C-S Park, Genome Research Center for Allergy and Respiratory Diseases, Division of Allergy and Respiratory Medicine, Soonchunhyang University Bucheon Hospital, Bucheon 140-743, Republic of Korea.

E-mail: schalr@schmc.ac.kr

or Professor HD Shin, Department of Life Science, Sogang University, 1 Shinsu-dong, Mapo-gu, Seoul 121-742, Republic of Korea.

E-mail: hdshin@sogang.ac.kr

Received 14 April 2011; revised 6 June 2011; accepted 8 June 2011; published online 28 July 2011 
Table 1 Clinical profiles of study subjects

\begin{tabular}{lccc}
\hline Clinical profiles & AERD $(\mathrm{n}=93)$ & ATA $(\mathrm{n}=96)$ & P-value \\
\hline Age year, mean (range) & $44.4(17-73)$ & $45.8(15-77)$ & $24 / 72$ \\
Sex (male/female) & $32 / 61$ & $6.45 / 12.90$ & 0.497 \\
Ex-smoker/Current smoker (\%) & $15.63 / 9.38$ & $4.88 \pm 4.19$ & 0.156 \\
Blood eosinophil (\%) & $6.29 \pm 5.80$ & $3.04 \pm 4.27$ & 0.219 \\
PC20, methacholine $\left(\mathrm{mg} \mathrm{ml}^{-1}\right)$ & $4.23 \pm 7.18$ & $309.54 \pm 426.04$ & 0.060 \\
Total IgE (IU ml - $^{-1}$ ) & $321.65 \pm 623.31$ & $0.94 \pm 2.76$ & 0.193 \\
Decline of FEV1 by aspirin provocation (\%) & $23.61 \pm 14.48$ & 56.99 & 0.001 \\
Positive rate of skin test (\%) & 61.46 & 0.532 \\
\hline
\end{tabular}

Abbreviations: AERD, aspirin exacerbated respiratory disease; ATA, aspirin-tolerant asthma; FEV1, forced expiratory volume in one second.

Value significant at $P<0.05$ is shown in bold.

Table 2 Polymorphisms of TAP1 and TAP2 investigated in this study

\begin{tabular}{|c|c|c|c|c|c|c|c|c|c|}
\hline \multirow{2}{*}{$\begin{array}{l}\text { Gene } \\
\text { TAP1 }\end{array}$} & \multirow{2}{*}{$\frac{S N P \text { ID }}{r s 2071481}$} & \multirow{2}{*}{$\frac{\text { Polymorphism }}{\text { A/G }}$} & \multirow{2}{*}{$\begin{array}{l}\text { Position } \\
\text { Intron }\end{array}$} & \multirow[t]{2}{*}{ Amino-acid change } & \multicolumn{3}{|c|}{ Genotype (n) } & \multirow{2}{*}{$\begin{array}{c}\text { MAF } \\
0.223\end{array}$} & \multirow{2}{*}{$\frac{H W E^{*}}{0.648}$} \\
\hline & & & & & $A A(109)$ & AG (60) & GG (10) & & \\
\hline & rs2284190 & $\mathrm{T} / \mathrm{C}$ & Intron & & TT (132) & $\mathrm{TC}(50)$ & CC (3) & 0.151 & 0.479 \\
\hline & rs4148880 & $A / G$ & Exon & Ile393Val & AA (124) & $A G(55)$ & GG (8) & 0.190 & 0.549 \\
\hline & rs2395269 & $\mathrm{T} / \mathrm{G}$ & Intron & & TT (125) & TG (52) & GG (8) & 0.184 & 0.391 \\
\hline & rs12529313 & $A / G$ & Intron & & $\mathrm{AA}(124)$ & $A G(55)$ & GG (8) & 0.190 & 0.549 \\
\hline & rs2071482 & $\mathrm{G} / \mathrm{T}$ & Intron & & GG (125) & GT (53) & TT (7) & 0.181 & 0.643 \\
\hline & rs735883 & $\mathrm{C} / \mathrm{T}$ & Intron & & $\mathrm{CC}(78)$ & CT (85) & TT (22) & 0.349 & 0.875 \\
\hline & rs1800453 & $A / G$ & Exon & Asp697Gly & $A A(130)$ & AG (48) & GG (7) & 0.168 & 0.341 \\
\hline & rs4711312 & $A / G$ & Intron & & $\mathrm{AA}(130)$ & $A G(48)$ & GG (7) & 0.168 & 0.341 \\
\hline & rs1057373 & $\mathrm{G} / \mathrm{T}$ & 3'UTR & & GG (132) & GT (46) & TT (7) & 0.162 & 0.248 \\
\hline & rs2071540 & $\mathrm{G} / \mathrm{A}$ & 3'near & & GG (61) & GA (94) & AA (30) & 0.416 & 0.535 \\
\hline & rs2071541 & $\mathrm{T} / \mathrm{C}$ & 3'near & & TT (127) & TC (50) & CC (8) & 0.178 & 0.289 \\
\hline \multirow[t]{31}{*}{ TAP2 } & rs3763366 & $C / G$ & 5'near & & CC (51) & CG (94) & GG (44) & 0.481 & 0.957 \\
\hline & rs4148870 & $\mathrm{G} / \mathrm{A}$ & Intron & & GG (55) & GA (89) & AA (43) & 0.468 & 0.546 \\
\hline & rs2071544 & $\mathrm{G} / \mathrm{A}$ & Intron & & GG (50) & GA (95) & AA (44) & 0.484 & 0.931 \\
\hline & rs2071465 & $\mathrm{G} / \mathrm{C}$ & Intron & & GG (89) & GC (78) & CC (19) & 0.312 & 0.755 \\
\hline & rs2239701 & $\mathrm{A} / \mathrm{G}$ & Intron & & $\mathrm{AA}(44)$ & GA (101) & GG (42) & 0.495 & 0.272 \\
\hline & $r s 241424$ & $\mathrm{C} / \mathrm{T}$ & Intron & & CC (49) & СТ (94) & TT (44) & 0.487 & 0.934 \\
\hline & rs3819721 & $\mathrm{G} / \mathrm{A}$ & Intron & & GG (101) & GA (72) & AA (14) & 0.267 & 0.814 \\
\hline & rs241426 & $\mathrm{T} / \mathrm{A}$ & Intron & & TT (74) & TA (91) & AA (22) & 0.361 & 0.453 \\
\hline & rs3819714 & $\mathrm{G} / \mathrm{A}$ & Intron & & GG (63) & GA (98) & AA (26) & 0.401 & 0.214 \\
\hline & rs241429 & $\mathrm{C} / \mathrm{T}$ & Intron & & CC (74) & СТ (86) & TT (27) & 0.374 & 0.804 \\
\hline & rs4148871 & $\mathrm{C} / \mathrm{T}$ & Intron & & CC (122) & CT (62) & TT (3) & 0.182 & 0.118 \\
\hline & rs241430 & $\mathrm{G} / \mathrm{A}$ & Intron & & GG (68) & GA (95) & $\mathrm{AA}(25)$ & 0.386 & 0.362 \\
\hline & $r s 241432$ & $\mathrm{~A} / \mathrm{C}$ & Intron & & $A A(66)$ & $A C(95)$ & $\mathrm{CC}(28)$ & 0.399 & 0.512 \\
\hline & rs4148873 & $\mathrm{G} / \mathrm{A}$ & Exon & Val379lle & GG (141) & GA (43) & $\mathrm{AA}(3)$ & 0.131 & 0.893 \\
\hline & rs2228397 & $\mathrm{G} / \mathrm{T}$ & Exon & $\begin{array}{l}\text { Synonymous } \\
\text { (Gly386Gly) }\end{array}$ & GG (90) & GT (78) & TT (19) & 0.310 & 0.730 \\
\hline & $r s 241433$ & $\mathrm{~T} / \mathrm{G}$ & Intron & & TT (63) & TG (96) & GG (28) & 0.406 & 0.381 \\
\hline & rs1015166 & $\mathrm{C} / \mathrm{T}$ & Intron & & CC (99) & CT (75) & TT (13) & 0.270 & 0.813 \\
\hline & rs4576294 & $\mathrm{G} / \mathrm{A}$ & Exon & $\begin{array}{l}\text { Synonymous } \\
\text { (Asn436Asn) }\end{array}$ & GG (177) & GA (10) & $A A(0)$ & 0.027 & 0.707 \\
\hline & $r s 241436$ & $\mathrm{C} / \mathrm{T}$ & Intron & & CC (57) & CT (82) & TT (48) & 0.476 & 0.098 \\
\hline & rs241437 & $\mathrm{C} / \mathrm{T}$ & Intron & & CC (52) & СТ (92) & TT (43) & 0.476 & 0.851 \\
\hline & $r s 241438$ & $\mathrm{G} / \mathrm{A}$ & Intron & & GG (49) & GA (91) & AA (48) & 0.497 & 0.662 \\
\hline & rs241439 & $\mathrm{C} / \mathrm{A}$ & Intron & & CC (52) & CA (91) & AA (44) & 0.479 & 0.733 \\
\hline & rs4148876 & $\mathrm{C} / \mathrm{T}$ & Exon/intron & Arg651Cys & CC (132) & CT (52) & TT (3) & 0.155 & 0.403 \\
\hline & rs241454 & $\mathrm{T} / \mathrm{C}$ & 3'UTR/intron & & TT (71) & TC (92) & CC (24) & 0.374 & 0.492 \\
\hline & rs10484565 & $\mathrm{G} / \mathrm{A}$ & 3’UTR/intron & & GG (146) & GA (38) & AA (3) & 0.118 & 0.772 \\
\hline & rs2857101 & $A / G$ & 3'UTR/intron & & $\mathrm{AA}(71)$ & AG (94) & GG (24) & 0.376 & 0.407 \\
\hline & rs13501 & $\mathrm{G} / \mathrm{A}$ & 3'UTR/intron & & GG (56) & GA (96) & AA (35) & 0.444 & 0.586 \\
\hline & rs1894411 & $A / G$ & 3'near/intron & & $\mathrm{AA}(141)$ & AG (42) & GG (5) & 0.138 & 0.390 \\
\hline & rs2856993 & $\mathrm{C} / \mathrm{G}$ & 3'near/intron & & CC (89) & CG (83) & GG (15) & 0.302 & 0.473 \\
\hline & rs2857103 & $\mathrm{G} / \mathrm{T}$ & 3'near/intron & & GG (56) & GT (96) & TT (35) & 0.444 & 0.586 \\
\hline & rs2621321 & $\mathrm{T} / \mathrm{C}$ & 3'near & & TT (81) & TC (88) & CC (18) & 0.332 & 0.399 \\
\hline
\end{tabular}

Abbreviations: HWE, Hardy-Weinberg equilibrium; MAF, minor allele frequency; SNP, single-nucleotide polymorphism; UTR, untranslated region.

${ }^{*} P$-value of deviation from HWE. 
bacterial infection in the upper respiratory tract and bronchiectasis in the lower respiratory tract. ${ }^{8}$ Furthermore, polymorphisms in TAP1 and TAP2 have been implicated in idiopathic bronchiectasis in children, ${ }^{9}$ and a polymorphism in TAP1 has been found to induce the risk of atopy. ${ }^{10}$

Because of the associations between the TAP complex and immune responses in the respiratory tracts, we hypothesized that genetic variations of TAP1 and TAP2 might be associated with AERD and/ or its related symptoms.

\section{MATERIALS AND METHODS}

\section{Study subjects}

Study subjects were recruited from hospitals of Soonchunhyang, Chungbuk National, Chonnam National, Seoul National and Chung-Ang Universities in Korea. Study protocols were approved by the Institutional Review Board of the hospitals where all subjects were recruited, and all subjects provided written informed consent. All patients who meet the guidelines of Global Initiative for Asthma (GINA) for the clinical symptoms of asthma showed histories of dyspnea and wheezing during the previous 12 months, along with one of the following: (1) $>15 \%$ increase in FEV1 or $>12 \%$ increase plus $200 \mathrm{ml}$ following inhalation of a short-acting bronchodilator, (2) $<10 \mathrm{mg} \mathrm{ml}^{-1}$ PC20 methacholine and (3) $>20 \%$ increase in FEV1 following 2 weeks of treatment with inhaled steroids and long-acting bronchodilators. Total IgE was determined using the UniCAP system (Pharmacia Diagnostics, Uppsala, Sweden). Oral aspirin challenge was performed with a slight modification in increasing doses of aspirin, ${ }^{11}$ following the guidelines of EAACI/GA2LEN. ${ }^{12}$ Changes in FEV1 were followed for $5 \mathrm{~h}$ after the last aspirin challenge dose. Aspirin-induced bronchospasms, as reflected by rate (\%) of FEV1 decline, were calculated as the pre-challenge FEV1 minus the post-challenge FEV1 divided by the prechallenge FEV1. On the basis of the oral aspirin provocation test, subjects were stratified into two groups as follows: patients who showed $20 \%$ or greater decrease in FEV1 or 15 to $19 \%$ decrease in FEV1 with naso-ocular or cutaneous reactions were classified as AERD cases, whereas asthmatics who showed less than 15\% decreases in FEV1 without naso-ocular or cutaneous reactions were grouped as aspirin-tolerant asthma (ATA) controls.

\section{Single-nucleotide polymorphism (SNP) selection and genotyping} Based on the minor allele frequency of Asian populations from the International HapMap Project database (http://hapmap.ncbi. nlm.nih.gov/index.html. en), a total of 43 common single-nucleotide polymorphisms (SNPs) (minor allele frequency $>0.05$ ) composed of 12 TAP1 SNPs and 31 TAP2 SNPs of were selected for genotyping. Genotyping was performed in a total of 189 asthma patients including 93 AERD patients and 96 ATA controls using TaqMan assay on the ABI prism 7900HT sequence detection system (Applied Biosystems, Foster City, CA, USA), along with assessment of data qualities by duplicate DNAs $(n=10)$. SNPs that did not meet the following criteria were excluded from association analyses: (1) a minimum call rate of $95 \%$; (2) no duplicate error; (3) Hardy-Weinberg equilibrium of $P>0.05$.

\section{Statistics}

Linkage disequilibrium (LD) of TAP1 and TAP2 polymorphisms was analyzed using the Haploview v4.1. software downloaded from the Broad Institute (http://www.broadinstitute.org/mpg/haploview). ${ }^{13} \mathrm{LD}$ coefficients $\left(\left|D^{\prime}\right|\right.$ and $\left.r^{2}\right)$ between all pairs of biallelic loci were used to determine LD among the SNPs.

a

TAP2 on chromosome $6 \mathrm{p} 21.3$

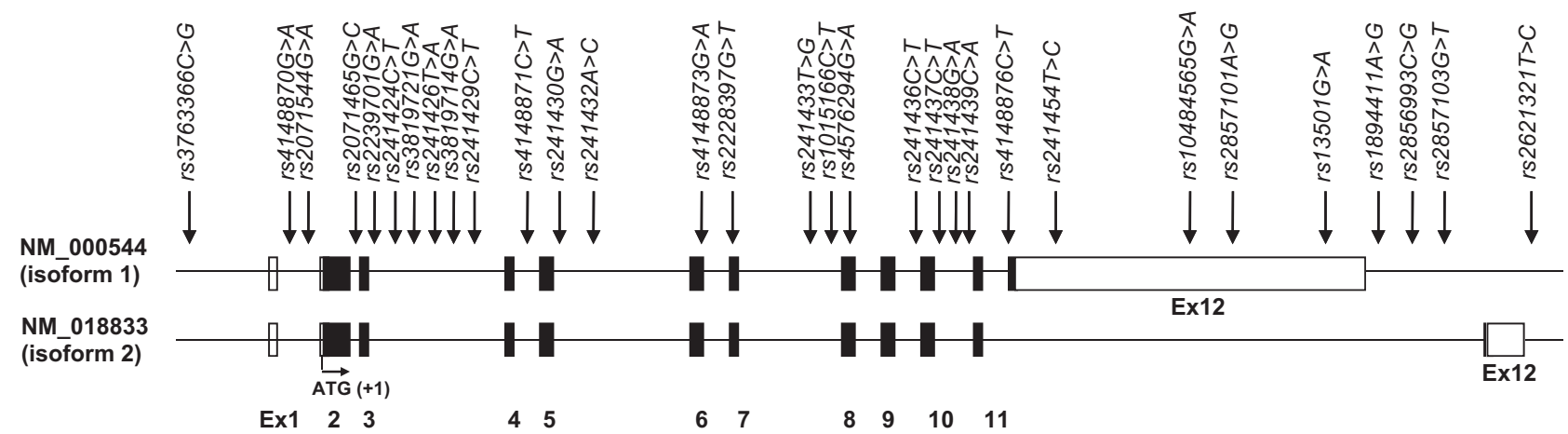

b

Haplotypes of TAP2

BL1

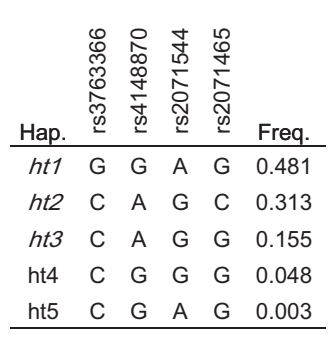

$\mathrm{BL2}$

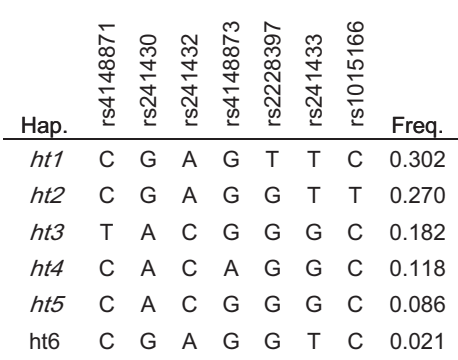

BL3

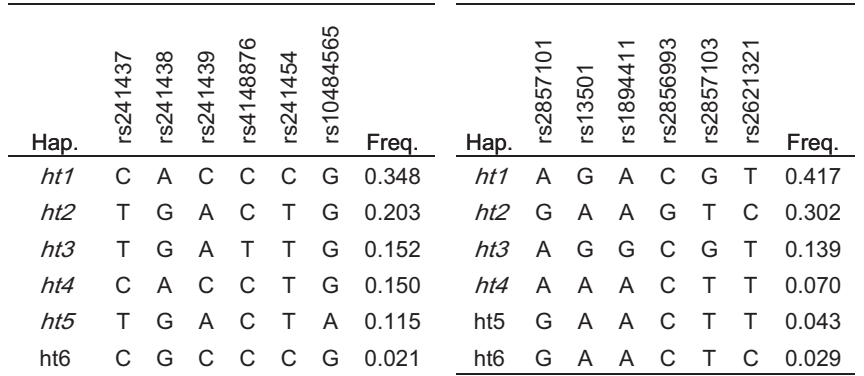

Others

0.021

Others

0.012

Figure 1 Physical map and haplotypes of TAP2. (a) Physical map of TAP2 and its SNPs genotyped in this study. This gene has two isoforms, NM_000544 and NM_018833, which are different in $3^{\prime}$ untranslated region (UTR), especially in exon 12 . The coding exons are represented by black blocks, and 5'UTR and 3'UTR by white blocks. (b) Haplotypes of TAP2. Haplotypes with frequency $>0.05$ (denoted as italics) are used for association analyses. BL, haplotype block. 
Haplotypes were inferred from the PHASE algorithm. ${ }^{14}$ Associations of each SNP and haplotype of the genes with AERD and its related symptoms were assessed using the statistical analysis system (SAS), with adjusting age, gender, smoking status and atopy as covariates.

\section{RESULTS}

Characteristics of study subjects

Clinical and demographic characteristics of 189 study subjects including 93 AERD cases and 96 ATA controls are presented in Table 1. The male-female ratio of the study subjects was at $\sim 1: 2$ for AERD and $\sim 1: 3$ for ATA, as expected of the differential gender ratio in adult asthma according to the Global Allergy and Asthma European Network (GA2LEN). Although comparisons of total IgE level and skin test showed no significant differences between the subgroups $(P>0.05)$, about 1.3-fold nominal increase in blood eosinophils of AERD patients compared with ATA controls was observed (Table 1). The FEV1 decline by aspirin provocation in the patient group was significantly higher than that in the control group $(P<0.001)$.

\section{Polymorphisms, LD and haplotypes of TAP1 and TAP2}

A total of 43 common SNPs (minor allele frequency >0.05), 12 SNPs in TAP1 and 31 SNPs in TAP2, were selected and successfully genotyped in 93 AERD patients and 96 ATA controls (Table 2). Four non-synonymous SNPs in coding regions (Ile393Val and Asp697Gly in TAP1; Val379Ile and Arg651Cys in TAP2) were included. In the case of TAP2, positions of eight SNPs are different depending on two isoforms, NM_000544 and NM_018833 (Figure 1a and Table 2). All SNPs showed no departure from Hardy-Weinberg equilibrium $(P>0.05$, Table 2$)$.
Pairwise comparisons of the selected SNPs revealed that, although TAP1 rs2071481 was excluded from the LD plot, SNPs in TAP1 were in one tight LD block (Supplementary Figure 1), whereas polymorphisms of TAP2 encompassed four LD blocks (Figure 2). Among the inferred haplotypes in TAP1 (Supplementary Figure 1) and TAP2 (Figure 1b), only common haplotypes with frequency over 0.05 were used for the haplotype association analysis. Because of the equivalences of haplotypes to SNPs ( $h t 1$ to rs 2071540, ht3 to rs1057373, ht4 to rs2284190 in TAP1 as shown in Supplementary Figure 1; BL1-ht1 to rs3763366, BL1- $h t 2$ to rs2071465, BL2-ht1 to rs2228397, BL2-ht2 to rs1015166, BL2-ht3 to $r s 4148871, B L 3-h t 3$ to $r s 4148876, B L 3-h t 5$ to $r s 10484565 ; B L 4-h t 2$ to $r s 2856993, B L 4-h t 3$ to $r s 1894411$ in TAP2 as shown in Figure 1b), some haplotypes were also excluded from the haplotype association analysis.

\section{Association analysis of polymorphisms in TAP1 and TAP2 with AERD and its related symptoms}

Logistic analyses that were adjusted by age, gender, smoking status and atopy as covariates using multiple models showed that none of the TAP1 polymorphisms/haplotypes were associated with both FEV1 decline by aspirin provocation and AERD development $(P>0.05$, Supplementary Tables 1 and 2). However, regression analysis revealed significant associations of seven polymorphisms and two haplotypes in TAP2 with FEV1 decline by aspirin provocation $(P=0.002-0.04$, Table 3). Except rs 241437 in block 3 of TAP2, most of minor homozygotes showed about twofold decline rate of FeV1 compared with major homozygotes. In particular, most significant polymorphisms were focused on the distinctive region between two transcripts of

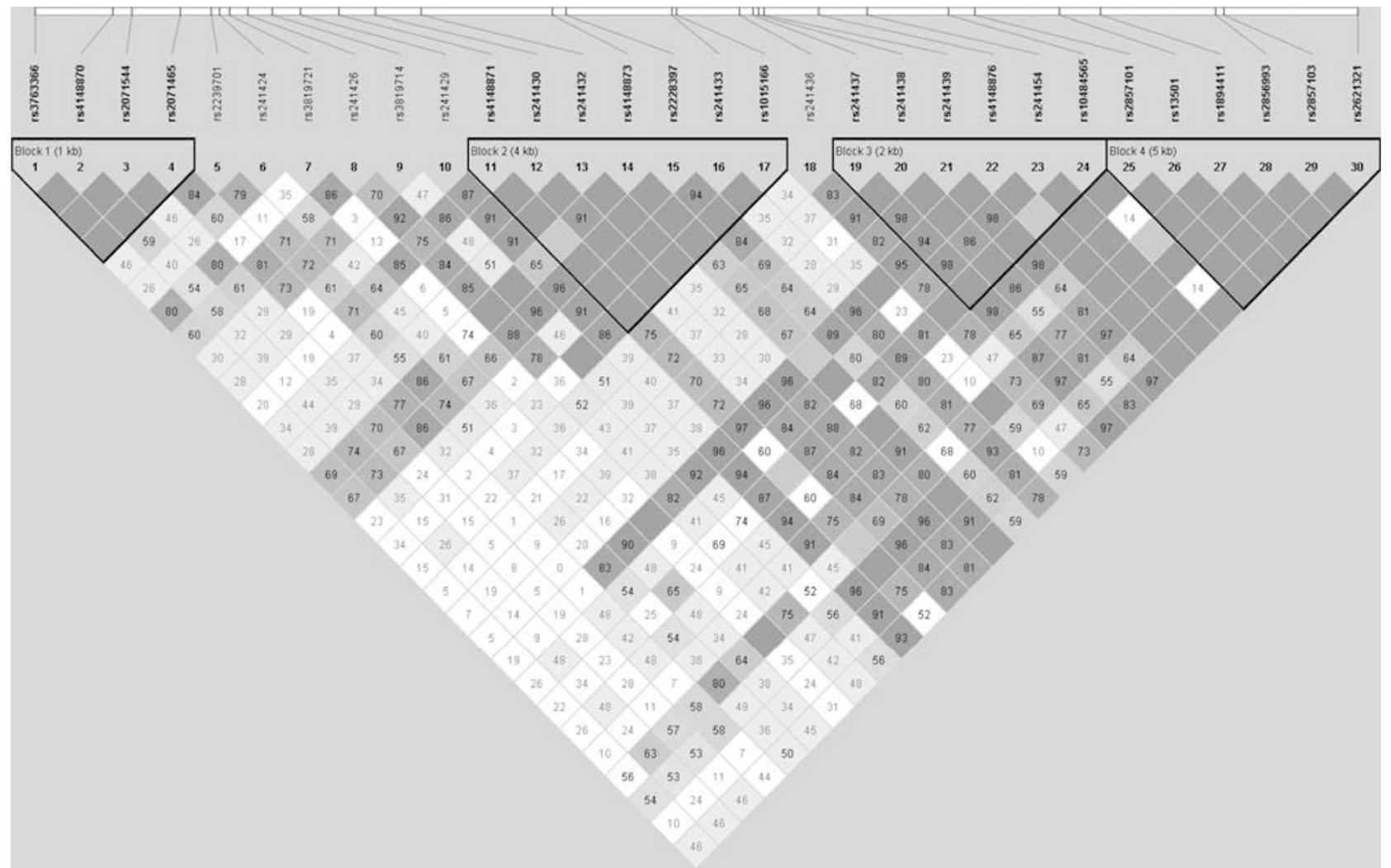

Figure 2 LD plot of TAP2 polymorphisms investigated in this study. TAP2 polymorphisms investigated in this study compose of four haplotype blocks. LD number in blocks represent values of multiallelic $D^{\prime}$. 
NM_000544 and NM_018833 (Figure 1a). Although significances were not high as the values in the association with FEV1 decline, nominal evidences in the association of two polymorphisms and one haplotype of TAP2 with AERD development were observed $(\mathrm{OR}=0.44-1.94, P=0.02-0.04$, Table 4).

\section{DISCUSSION}

Although the exact mechanism underlying aspirin hypersensitivity has not been elucidated, AERD, also referred to aspirin-intolerant asthma, is often severe and even can be life threatening. Blockage of cyclooxygenase (COX) pathway, which converts arachidonic acid into prostaglandins, by aspirin eventually results in the diversion of arachidonic acid metabolites to CysLTs via the 5-lipoxygenase pathway., ${ }^{2,4}$ Overproduction of CysLTs and deficiency of prostaglandin $\mathrm{E}_{2}$ in bronchial fibroblasts by COX inhibition have been proposed to have crucial roles in AERD development. ${ }^{4,15}$ However, along with conflicting results for the associations between polymorphisms of genes in leukotriene and COX pathways ${ }^{16-18}$ genes on other pathways including bronchial hyperresponsiveness by MHC or structural genes have provided new insights for AERD pathogenesis. ${ }^{5,19}$ Therefore, although further replications and functional evaluations are required, our findings on the associations of TAP2 with AERD-related symptoms, particularly with FEV1 decline by aspirin provocation, might provide evidences for the role of the gene in respiratory deficiencies.

Table 3 Associations of TAP2 polymorphisms and haplotypes with decline of FEV1 by aspirin provocation

\begin{tabular}{|c|c|c|c|c|c|c|c|c|}
\hline Haplotype block & SNP or haplotype & Position & $C / C$ & $C / R$ & $R / R$ & $\mathrm{~Pa}$ & $\mathrm{~Pb}$ & Pc \\
\hline \multirow[t]{11}{*}{ Block 1} & rs3763366 & 5'near & $51(12.05 \pm 15.52)$ & $94(12.43 \pm 16.33)$ & $44(11.41 \pm 13.15)$ & 0.97 & 0.88 & 0.82 \\
\hline & rs4148870 & Intron & $55(10.90 \pm 12.92)$ & $89(12.39 \pm 16.94)$ & $43(12.66 \pm 15.29)$ & 0.65 & 0.60 & 0.82 \\
\hline & rs2071544 & Intron & $50(12.34 \pm 15.54)$ & $95(12.28 \pm 16.31)$ & $44(11.41 \pm 13.15)$ & 0.90 & 0.99 & 0.82 \\
\hline & rs2071465 & Intron & $89(12.35 \pm 16.45)$ & $78(11.50 \pm 14.84)$ & $19(12.19 \pm 13.64)$ & 0.84 & 0.78 & 0.98 \\
\hline & TAP2-BL1-ht3 & & $134(11.36 \pm 14.05)$ & $46(13.16 \pm 17.90)$ & $6(17.30 \pm 25.32)$ & 0.40 & 0.48 & 0.47 \\
\hline & rs2239701 & Intron & $42(10.11 \pm 12.71)$ & $101(13.44 \pm 16.57)$ & $44(10.55 \pm 14.99)$ & 0.79 & 0.33 & 0.59 \\
\hline & rs241424 & Intron & $49(9.63 \pm 15.77)$ & $94(13.59 \pm 16.14)$ & $44(11.30 \pm 13.20)$ & 0.53 & 0.22 & 0.81 \\
\hline & rs3819721 & Intron & $101(12.50 \pm 15.18)$ & $72(10.96 \pm 14.00)$ & $14(13.95 \pm 23.34)$ & 0.84 & 0.61 & 0.62 \\
\hline & rs241426 & Intron & $74(11.83 \pm 15.99)$ & $91(12.02 \pm 14.33)$ & $22(12.60 \pm 18.27)$ & 0.73 & 0.76 & 0.80 \\
\hline & rs3819714 & Intron & $63(10.66 \pm 14.01)$ & $98(12.34 \pm 15.48)$ & $26(14.04 \pm 18.48)$ & 0.35 & 0.41 & 0.51 \\
\hline & rs241429 & Intron & $74(13.69 \pm 17.06)$ & $86(10.97 \pm 13.18)$ & $27(10.75 \pm 17.34)$ & 0.18 & 0.12 & 0.64 \\
\hline \multirow[t]{11}{*}{ Block 2} & rs4148871 & Intron & $122(12.47 \pm 16.30)$ & $62(11.70 \pm 13.75)$ & $3(-0.33 \pm 1.53)$ & 0.28 & 0.43 & 0.14 \\
\hline & rs241430 & Intron & $68(13.86 \pm 17.16)$ & $95(11.29 \pm 14.08)$ & $25(9.99 \pm 15.11)$ & 0.14 & 0.10 & 0.51 \\
\hline & rs241432 & Intron & $66(14.28 \pm 17.23)$ & $95(11.33 \pm 14.11)$ & $28(9.52 \pm 14.58)$ & 0.07 & 0.06 & 0.34 \\
\hline & rs4148873 & Exon & $141(13.04 \pm 16.38)$ & $43(7.86 \pm 10.62)$ & $3(23.23 \pm 17.72)$ & 0.22 & 0.09 & 0.27 \\
\hline & rs2228397 & Exon & $90(10.73 \pm 15.26)$ & $78(12.26 \pm 15.05)$ & $19(17.09 \pm 17.29)$ & 0.13 & 0.27 & 0.13 \\
\hline & rs241433 & Intron & $63(13.59 \pm 16.92)$ & $96(11.70 \pm 14.64)$ & $28(9.52 \pm 14.58)$ & 0.14 & 0.16 & 0.35 \\
\hline & rs1015166 & Intron & $99(11.31 \pm 14.23)$ & $75(13.87 \pm 16.90)$ & $13(6.67 \pm 14.55)$ & 0.85 & 0.46 & 0.32 \\
\hline & TAP2-BL2-ht4 & & $145(12.69 \pm 16.31)$ & $38(8.45 \pm 10.82)$ & $3(23.23 \pm 17.72)$ & 0.43 & 0.23 & 0.27 \\
\hline & TAP2-BL2-ht5 & & $156(12.31 \pm 15.12)$ & $28(8.98 \pm 15.68)$ & $2(29.50 \pm 34.65)$ & 0.83 & 0.48 & 0.09 \\
\hline & rs4576294 & Exon & $177(11.86 \pm 14.96)$ & $10(14.77 \pm 22.84)$ & . & 0.51 & 0.51 & . \\
\hline & rs241436 & Intron & $57(13.24 \pm 15.99)$ & $82(13.45 \pm 15.93)$ & $48(8.11 \pm 13.33)$ & 0.13 & 0.55 & 0.05 \\
\hline \multirow[t]{9}{*}{ Block 3} & rs241437 & Intron & $52(14.24 \pm 16.71)$ & $92(12.76 \pm 15.39)$ & $43(7.72 \pm 13.18)$ & 0.04 & 0.22 & 0.04 \\
\hline & rs241438 & Intron & $49(9.11 \pm 14.28)$ & $91(12.17 \pm 14.85)$ & $48(14.80 \pm 17.14)$ & 0.07 & 0.12 & 0.16 \\
\hline & rs241439 & Intron & $52(14.62 \pm 16.63)$ & $91(12.24 \pm 15.21)$ & $44(8.46 \pm 13.92)$ & 0.05 & 0.14 & 0.07 \\
\hline & rs4148876 & Exon/intron & $132(12.76 \pm 16.31)$ & $52(10.84 \pm 13.07)$ & $3(-0.33 \pm 1.53)$ & 0.15 & 0.25 & 0.14 \\
\hline & rs241454 & 3'UTR/intron & $71(9.10 \pm 14.09)$ & $92(12.71 \pm 15.00)$ & $24(17.93 \pm 19.01)$ & 0.007 & 0.03 & 0.03 \\
\hline & rs10484565 & 3’UTR/intron & $146(11.61 \pm 15.33)$ & $38(14.63 \pm 15.83)$ & $3(-1.57 \pm 2.10)$ & 0.78 & 0.44 & 0.12 \\
\hline & TAP2-BL3-ht1 & & $79(10.12 \pm 14.46)$ & $86(11.91 \pm 14.78)$ & $21(19.38 \pm 19.84)$ & 0.02 & 0.13 & 0.01 \\
\hline & TAP2-BL3-ht2 & & $118(13.48 \pm 15.75)$ & $60(9.45 \pm 14.14)$ & $8(9.14 \pm 19.45)$ & 0.09 & 0.07 & 0.67 \\
\hline & TAP2-BL3-ht4 & & $135(12.27 \pm 15.93)$ & $46(11.02 \pm 13.94)$ & $5(13.42 \pm 18.52)$ & 0.62 & 0.61 & 0.87 \\
\hline \multirow[t]{8}{*}{ Block 4} & rs2857101 & 3'UTR/intron & $71(9.10 \pm 14.09)$ & $94(12.86 \pm 14.88)$ & $24(17.93 \pm 19.01)$ & 0.006 & 0.03 & 0.03 \\
\hline & rs13501 & 3'UTR/intron & $56(9.89 \pm 14.61)$ & $96(10.89 \pm 14.03)$ & $35(18.48 \pm 18.72)$ & 0.007 & 0.17 & 0.002 \\
\hline & rs1894411 & 3'near/intron & $141(12.32 \pm 15.86)$ & $42(10.89 \pm 13.67)$ & $5(13.94 \pm 17.92)$ & 0.65 & 0.59 & 0.98 \\
\hline & rs2856993 & 3'near/intron & $89(9.34 \pm 14.28)$ & $83(13.57 \pm 15.12)$ & $15(19.22 \pm 20.48)$ & 0.004 & 0.02 & 0.03 \\
\hline & rs2857103 & 3'near/intron & $56(9.89 \pm 14.61)$ & $96(10.89 \pm 14.03)$ & $35(18.48 \pm 18.72)$ & 0.007 & 0.17 & 0.002 \\
\hline & rs2621321 & 3'near & $81(9.39 \pm 14.72)$ & $88(12.88 \pm 14.46)$ & $18(19.58 \pm 20.31)$ & 0.007 & 0.04 & 0.02 \\
\hline & TAP2-BL4-ht1 & & $64(15.56 \pm 17.49)$ & $88(10.38 \pm 13.34)$ & $34(9.47 \pm 15.73)$ & 0.02 & 0.01 & 0.25 \\
\hline & TAP2-BL4-ht4 & & $161(11.95 \pm 15.32)$ & $24(12.79 \pm 16.77)$ & $1(0.80)$ & 0.90 & 0.79 & 0.55 \\
\hline
\end{tabular}

Abbreviations: SNP, single-nucleotide polymorphism; UTR, untranslated region.

$\mathrm{C} / \mathrm{C}, \mathrm{C} / \mathrm{R}$ and $\mathrm{R} / \mathrm{R}$ indicate the homozygote of common allele, the heterozygote and the homozygote of rare allele, respectively.

$P$-value is adjusted for age, sex, smoking and atopy as co-variables.

$P a, P b$, and $P c$ indicate the $P$-value of co-dominant, dominant, and recessive models, respectively.

$B L 1$-ht1 and BL1-ht2 are equivalent to rs3763366 and rs2071465, respectively.

BL2-ht1, BL2-ht2 and BL2-ht3 are equivalent to rs2228397, rs 1015166 and rs4148871, respectively.

$B L 3-h t 3$ and $B L 3-h t 5$ are equivalent to $r s 4148876$ and $r s 10484565$, respectively.

BL4-ht2 and BL4-ht3 are equivalent to rs2856993 and rs1894411, respectively.

Values significant at $P<0.05$ are shown in bold. 
The HLA system, also described as MHC, is a key feature of the immune system. Although important roles of TAP molecules encoded within the MHC class II region have been elucidated in many immune processes ${ }^{20}$ few studies on the relations of TAP to asthma and its related phenotypes have been published. According to the clinical manifestations in patients with TAP deficiency syndrome, almost all the patients show ear/nose/throat diseases (for example, chronic sinusitis and nasal polyps), and $\sim 80 \%$ of the patients exhibit lung diseases (for example, chronic spastic bronchitis and recurrent bacterial infection) ${ }^{8}$ Our preliminary results on the significant associations between TAP2 variants and the FEV1-related phenotype suggest that dysfunctions of TAP2 could lead deficits in lower airways.

Polymorphisms in the TAP1 and TAP2 have shown discriminative association results depending on the nature of the allergic diseases. Non-synonymous SNPs and haplotypes of TAP1 have been revealed to be associated with allergic rhinitis, whereas those of TAP2 showed no associations. ${ }^{21}$ In addition, association analysis of TAP1 polymorphisms, but not tested for TAP2, has provided a strong relation to atopy. ${ }^{10}$ Meanwhile, polymorphisms of both TAP1 and TAP2, particularly with a portion of the same non-synonymous SNPs investigated

Table 4 Associations of TAP2 polymorphisms and haplotypes with the risk of AERD

\begin{tabular}{|c|c|c|c|c|c|c|c|c|c|c|}
\hline \multirow[b]{2}{*}{ Haplotype block } & \multirow[b]{2}{*}{ SNP or haplotype } & \multirow[b]{2}{*}{ Position } & \multicolumn{2}{|c|}{$M A F$} & \multicolumn{2}{|l|}{ Co-dominant } & \multicolumn{2}{|l|}{ Dominant } & \multicolumn{2}{|l|}{ Recessive } \\
\hline & & & $A E R D(\mathrm{n}=93)$ & ATA $(\mathrm{n}=96)$ & OR $(95 \%$ CI) & $P$ & OR $(95 \% \mathrm{Cl})$ & $\mathrm{P}$ & OR $(95 \% \mathrm{Cl})$ & $P$ \\
\hline \multirow[t]{11}{*}{ Block 1} & rs3763366 & 5'near & 0.484 & 0.479 & $1.05(0.70-1.59)$ & 0.80 & $1.02(0.53-1.97)$ & 0.94 & $1.13(0.56-2.27)$ & 0.73 \\
\hline & rs4148870 & Intron & 0.473 & 0.464 & $1.00(0.67-1.50)$ & 0.98 & $1.00(0.53-1.92)$ & 0.99 & $1.01(0.50-2.02)$ & 0.98 \\
\hline & rs2071544 & Intron & 0.484 & 0.484 & $1.04(0.69-1.56)$ & 0.87 & $0.98(0.51-1.89)$ & 0.95 & $1.13(0.56-2.27)$ & 0.73 \\
\hline & rs2071465 & Intron & 0.322 & 0.302 & $1.09(0.70-1.70)$ & 0.70 & $1.10(0.61-1.98)$ & 0.76 & $1.17(0.45-3.07)$ & 0.75 \\
\hline & TAP2-BL1-ht3 & & 0.150 & 0.161 & $0.88(0.50-1.53)$ & 0.64 & $0.92(0.48-1.77)$ & 0.80 & $0.50(0.09-2.94)$ & 0.45 \\
\hline & rs2239701 & Intron & 0.495 & 0.516 & $0.95(0.62-1.45)$ & 0.80 & $1.09(0.54-2.18)$ & 0.81 & $0.80(0.40-1.59)$ & 0.52 \\
\hline & rs241424 & Intron & 0.516 & 0.458 & $1.29(0.85-1.95)$ & 0.23 & $1.55(0.79-3.03)$ & 0.20 & $1.26(0.64-2.50)$ & 0.51 \\
\hline & rs3819721 & Intron & 0.231 & 0.302 & $0.68(0.42-1.09)$ & 0.11 & $0.69(0.38-1.24)$ & 0.21 & $0.40(0.12-1.35)$ & 0.14 \\
\hline & rs241426 & Intron & 0.374 & 0.349 & $1.18(0.75-1.84)$ & 0.48 & $1.41(0.77-2.58)$ & 0.27 & $0.90(0.36-2.24)$ & 0.81 \\
\hline & rs3819714 & Intron & 0.401 & 0.401 & 0.99 (0.63-1.53) & 0.95 & $0.96(0.52-1.78)$ & 0.90 & $1.02(0.44-2.38)$ & 0.96 \\
\hline & $r s 241429$ & Intron & 0.346 & 0.401 & $0.75(0.49-1.15)$ & 0.19 & $0.77(0.42-1.42)$ & 0.40 & $0.54(0.23-1.28)$ & 0.16 \\
\hline \multirow[t]{11}{*}{ Block 2} & rs4148871 & Intron & 0.176 & 0.188 & $0.87(0.49-1.54)$ & 0.62 & $0.98(0.53-1.82)$ & 0.95 & . & . \\
\hline & $r s 241430$ & Intron & 0.359 & 0.411 & $0.74(0.47-1.16)$ & 0.18 & $0.70(0.37-1.29)$ & 0.25 & $0.64(0.27-1.54)$ & 0.32 \\
\hline & rs241432 & Intron & 0.366 & 0.432 & $0.70(0.45-1.08)$ & 0.11 & $0.64(0.34-1.20)$ & 0.16 & $0.61(0.26-1.39)$ & 0.24 \\
\hline & rs4148873 & Exon & 0.126 & 0.135 & $0.88(0.47-1.63)$ & 0.68 & $0.82(0.42-1.63)$ & 0.57 & $1.57(0.13-18.53)$ & 0.72 \\
\hline & rs2228397 & Exon & 0.346 & 0.276 & $1.40(0.89-2.19)$ & 0.14 & $1.40(0.78-2.52)$ & 0.26 & $1.97(0.72-5.41)$ & 0.19 \\
\hline & $r s 241433$ & Intron & 0.374 & 0.438 & $0.70(0.45-1.10)$ & 0.12 & $0.64(0.34-1.22)$ & 0.17 & $0.62(0.27-1.42)$ & 0.26 \\
\hline & rs1015166 & Intron & 0.275 & 0.266 & $1.11(0.69-1.77)$ & 0.67 & $1.26(0.70-2.26)$ & 0.44 & $0.75(0.23-2.43)$ & 0.63 \\
\hline & TAP2-BL2-ht4 & & 0.122 & 0.115 & $1.03(0.54-1.94)$ & 0.94 & $0.99(0.49-2.01)$ & 0.98 & $1.61(0.14-18.90)$ & 0.71 \\
\hline & TAP2-BL2-ht5 & & 0.061 & 0.109 & $0.53(0.24-1.14)$ & 0.10 & $0.46(0.20-1.05)$ & 0.07 & $1.30(0.08-21.36)$ & 0.86 \\
\hline & rs4576294 & Exon & 0.022 & 0.031 & $0.67(0.17-2.60)$ & 0.57 & $0.67(0.17-2.60)$ & 0.57 & . & . \\
\hline & $r s 241436$ & Intron & 0.434 & 0.516 & $0.77(0.52-1.14)$ & 0.19 & $1.02(0.54-1.93)$ & 0.95 & $0.44(0.22-0.89)$ & 0.02 \\
\hline \multirow[t]{9}{*}{ Block 3} & $r s 241437$ & Intron & 0.434 & 0.516 & $0.74(0.49-1.12)$ & 0.15 & $0.85(0.44-1.62)$ & 0.61 & $0.50(0.24-1.03)$ & 0.06 \\
\hline & $r s 241438$ & Intron & 0.543 & 0.453 & $1.40(0.93-2.12)$ & 0.11 & $1.92(0.97-3.81)$ & 0.06 & $1.31(0.67-2.56)$ & 0.43 \\
\hline & $r s 241439$ & Intron & 0.434 & 0.521 & $0.72(0.47-1.08)$ & 0.11 & $0.75(0.39-1.44)$ & 0.39 & $0.53(0.26-1.08)$ & 0.08 \\
\hline & rs4148876 & Exon/intron & 0.143 & 0.167 & $0.80(0.44-1.44)$ & 0.45 & $0.90(0.47-1.71)$ & 0.74 & . & . \\
\hline & rs241454 & 3'UTR/intron & 0.418 & 0.333 & $1.52(0.97-2.39)$ & 0.07 & $1.87(1.01-3.47)$ & 0.05 & $1.39(0.58-3.37)$ & 0.46 \\
\hline & rs10484565 & 3'UTR/Intron & 0.126 & 0.109 & $1.26(0.67-2.39)$ & 0.47 & $1.58(0.78-3.22)$ & 0.21 & . & . \\
\hline & TAP2-BL3-ht1 & & 0.383 & 0.307 & $1.46(0.93-2.28)$ & 0.10 & $1.60(0.88-2.91)$ & 0.13 & $1.65(0.64-4.23)$ & 0.30 \\
\hline & TAP2-BL3-ht2 & & 0.161 & 0.245 & $0.59(0.34-1.00)$ & 0.05 & $0.50(0.27-0.94)$ & 0.03 & $0.72(0.16-3.21)$ & 0.67 \\
\hline & TAP2-BL3-ht4 & & 0.156 & 0.146 & $1.02(0.58-1.80)$ & 0.95 & $1.13(0.59-2.17)$ & 0.72 & $0.46(0.07-3.02)$ & 0.42 \\
\hline \multirow[t]{8}{*}{ Block 4} & rs2857101 & 3'UTR/intron & 0.419 & 0.333 & $1.54(0.98-2.43)$ & 0.06 & $1.94(1.05-3.60)$ & 0.04 & $1.36(0.56-3.27)$ & 0.50 \\
\hline & rs13501 & 3'UTR/intron & 0.484 & 0.406 & $1.47(0.95-2.28)$ & 0.08 & $1.45(0.76-2.77)$ & 0.26 & $1.98(0.92-4.28)$ & 0.08 \\
\hline & rs1894411 & 3'near/intron & 0.130 & 0.146 & $0.83(0.46-1.48)$ & 0.53 & $0.86(0.44-1.68)$ & 0.65 & $0.49(0.08-3.19)$ & 0.46 \\
\hline & rs2856993 & 3’near/intron & 0.341 & 0.266 & $1.51(0.94-2.45)$ & 0.09 & $1.74(0.96-3.17)$ & 0.07 & $1.37(0.45-4.12)$ & 0.58 \\
\hline & rs2857103 & 3'near/intron & 0.484 & 0.406 & $1.47(0.95-2.28)$ & 0.08 & $1.45(0.76-2.77)$ & 0.26 & $1.98(0.92-4.28)$ & 0.08 \\
\hline & rs2621321 & 3'near & 0.374 & 0.292 & $1.51(0.95-2.41)$ & 0.08 & $1.75(0.96-3.21)$ & 0.07 & $1.43(0.52-3.93)$ & 0.49 \\
\hline & TAP2-BL4-ht1 & & 0.389 & 0.448 & $0.77(0.51-1.18)$ & 0.23 & $0.72(0.39-1.34)$ & 0.30 & $0.69(0.32-1.50)$ & 0.35 \\
\hline & TAP2-BL4-ht4 & & 0.067 & 0.073 & $0.99(0.44-2.24)$ & 0.98 & $1.07(0.45-2.54)$ & 0.87 & . & . \\
\hline
\end{tabular}

Abbreviations: AERD, aspirin exacerbated respiratory disease; ATA, aspirin-tolerant asthma; $\mathrm{Cl}$, confidence interval; MAF, minor allele frequency; OR, odds ratio; SNP, single-nucleotide polymorphism; UTR, untranslated region.

$P$-value is adjusted for age, sex, smoking and atopy as co-variables.

$B L 1-h t 1$ and $B L 1-h t 2$ are equivalent to $r s 3763366$ and $r s 2071465$, respectively.

BL2-ht1, BL2-ht2 and BL2-ht3 are equivalent to rs2228397, rs 1015166 and rs4148871, respectively.

$B L 3-h t 3$ and BL3-ht5 are equivalent to $r$ r 4148876 and $r s 10484565$, respectively.

$B L 4-h t 2$ and $B L 4-h t 3$ are equivalent to rs2856993 and $r s 1894411$, respectively.

Values significant at $P<0.05$ are shown in bold. 
in the association with allergic rhinitis, have been found to induce susceptibility to bronchiectasis in children. ${ }^{9}$ On the other hand, only the variants in TAP2 have been revealed to be a potential risk factor for systemic lupus erythematosus. ${ }^{22}$ Therefore, results from previous studies and the current report suggest that there might be complex and/or differential TAP functions in the transport process and immune response regulation.

In this study, the strength of association was increased in the $3^{\prime}$ region of TAP2 isoform 1 (NM_000544) and isoform 2 (NM_018833), suggesting that SNPs in the region might have a role in the regulation of the gene. The TAP2 isoform 2 (NM_018833; also termed as TAP2iso) derived from alternative splicing has been found to be normally co-expressed with isoform 1 (NM_000544), but has exhibited distinct functions. ${ }^{23}$ Furthermore, functional polymorphisms in the peptide C-terminal residue of TAP2 induce a change in substrate selectivity. ${ }^{24}$ Therefore, although functional evaluations are needed, it is suggested that several polymorphisms of TAP2 showing significant associations with FEV1 decline by aspirin provocation might contribute to additional immune diversity, especially with a possible effect on the selection process of antigen peptides that have a role in the pathogenesis of related conditions.

As expression quantitative trait loci are regions of the genome that regulate expression levels of mRNAs or proteins, we used the expression quantitative trait loci browser (http://eqtl.uchicago.edu/cgi-bin/ gbrowse/eqtl/) to confirm whether the risk SNPs of TAP2 could have an effect on the expression of the protein and/or mRNA. As a result, among six polymorphisms of expression quantitative trait loci for TAP2 (Supplementary Figure 2), rs13501 was found to act as a potential cis-regulator for TAP2 expression, with an expression quantitative trait loci score of 5.706 (Supplementary Table 3). To investigate potential polymorphisms with significant functions in the gene, additional in silico analyses of potential branch point site for alternative splicing using EMBL-EBI splice-site prediction (http:// www.ebi.ac.uk/asd-srv/wb.cgi?method=2) and putative binding site for regulators using the Signal Scan program (http://www-bimas.cit. nih.gov/molbio/signal/) were performed. Nevertheless, none of the significantly associated TAP2 polymorphisms were predicted as a functional variant.

Because of the association of $H L A-D P B 1^{*} 0301$ with AERD in Koreans, ${ }^{25}$ further analysis investigating the LD between TAP2 and HLA-DPB1 was performed using data from Asian populations (Japanese and Chinese) provided by the International HapMap Project database (http://hapmap.ncbi.nlm.nih.gov/index.html.en). However, TAP2 is not in LD with HLA-DPB1 (Supplementary Figure 3), suggesting that the potential association between TAP2 polymorphisms and obstructive diseases may not be related with HLA-DPB1. Also, in additional analysis of LD near TAP2 in Asian populations from the International HapMap Project, TAP2 showed no LD with other genes in the nearby region (Supplementary Figure 4).

Recent studies have reported associations of the genetic variations in many genes on the arachidonate, immune response and inflammation pathways, such as leukotriene C4 synthase (LTC4S), ${ }^{26,27}$ arachidonate 5-lipoxygenase $(A L O X 5)^{16}$ and MHC class II, DP beta 1 (HLA$D P B 1),{ }^{25}$ with aspirin hypersensitivity in asthmatics. However, conflicting results of the associations between polymorphisms of the genes and AERD have been reported, suggesting that underlying mechanisms of AERD pathogenesis may be more complicated than previously thought. Therefore, further replications and investigations with other candidate genes are required in order to comprehensively identify the exact genetic mechanisms of AERD etiology and its related phenotypes.
Genetic predisposition of TAP2 to the diffuse panbronchiolitis, a chronic inflammatory lung disease (as classified by the GOLD guidelines; http://www.goldcopd.org/) that affects the upper and lower respiratory tracts, has been observed. ${ }^{28}$ In addition, considering that TAP located on the endoplasmic reticulum membrane transports peptides from the cytoplasm into the endoplasmic reticulum and that endoplasmic reticulum stress (for example, by the affected translocation of peptides) contributes to the pathogenesis of chronic obstructive pulmonary disease, ${ }^{29,30}$ it is suggested that genetic variations of TAP2 could be risk factors of pulmonary functional deficiencies. Although limitations of this study include insufficient sample size, considering that FEV1 decline is a criterion of total pulmonary function and is associated with bronchospasm by aspirin provocation, our preliminary results might provide clinically relevant information for the potential involvement of TAP2, rather than TAP1, in respiratory deficiencies.

\section{ACKNOWLEDGEMENTS}

This work was supported by Grant number M1-0302-00-0073 from the Korea Science and Engineering Foundation (KOSEF) funded by the Korean government (MEST) (Number 2009-0080157), Grant from the Korea Health 21 R\&D Project (A010249) and Basic Science Research Program through the National Research Foundation of Korea (NRF) funded by the MEST (Number 20100007857).

1 Hedman, J., Kaprio, J., Poussa, T. \& Nieminen, M. M. Prevalence of asthma, aspirin intolerance, nasal polyposis and chronic obstructive pulmonary disease in a populationbased study. Int. J. Epidemiol. 28, 717-722 (1999).

2 Szczeklik, A. \& Stevenson, D. D. Aspirin-induced asthma: advances in pathogenesis, diagnosis, and management. J. Allergy. Clin. Immunol. 111, 913-921; quiz 922 (2003).

3 Bel, E. H. Clinical phenotypes of asthma. Curr. Opin. Pulm. Med. 10, 44-50 (2004).

4 Babu, K. S. \& Salvi, S. S. Aspirin and asthma. Chest 118, 1470-1476 (2000).

5 Koppelman, G. H., Meyers, D. A., Howard, T. D., Zheng, S. L., Hawkins, G. A., Ampleford, E. J. et al. Identification of PCDH1 as a novel susceptibility gene for bronchial hyperresponsiveness. Am. J. Respir. Crit. Care Med. 180, 929-935 (2009).

6 Pasaje, C. F., Kim, J. H., Park, B. L., Cheong, H. S., Chun, J. Y., Park, T. J. et al. Association of SLC6A12 variants with aspirin-intolerant asthma in a Korean population. Ann. Hum. Genet. 74, 326-334 (2010).

7 Alberts, P., Daumke, O., Deverson, E. V., Howard, J. C. \& Knittler, M. R. Distinct functional properties of the TAP subunits coordinate the nucleotide-dependent transport cycle. Curr. Biol. 11, 242-251 (2001).

8 Gadola, S. D., Moins-Teisserenc, H. T., Trowsdale, J., Gross, W. L. \& Cerundolo, V. TAP deficiency syndrome. Clin. Exp. Immunol. 121, 173-178 (2000).

9 Dogru, D., Ozbas Gerceker, F., Yalcin, E., Cobanoglu, N., Pekcan, S., Ozcelik, U. et al. The role of TAP1 and TAP2 gene polymorphism in idiopathic bronchiectasis in children. Pediatr. Pulmonol. 42, 237-241 (2007).

10 Ismail, A., Bousaffara, R., Kaziz, J., Zili, J., el Kamel, A., Tahar Sfar, M. et al. Polymorphism in transporter antigen peptides gene (TAP1) associated with atopy in Tunisians. J. Allergy Clin. Immunol. 99, 216-223 (1997).

11 Cormican, L. J., Farooque, S., Altmann, D. R. \& Lee, T. H. Improvements in an oral aspirin challenge protocol for the diagnosis of aspirin hypersensitivity. Clin. Exp. Allergy 35, 717-722 (2005)

12 Nizankowska-Mogilnicka, E., Bochenek, G., Mastalerz, L., Swierczynska, M., Picado, C., Scadding, G. et al. EAACI/GA2LEN guideline: aspirin provocation tests for diagnosis of aspirin hypersensitivity. Allergy 62, 1111-1118 (2007).

13 Barrett, J. C., Fry, B., Maller, J. \& Daly, M. J. Haploview: analysis and visualization of LD and haplotype maps. Bioinformatics 21, 263-265 (2005).

14 Stephens, M., Smith, N. J. \& Donnelly, P. A new statistical method for haplotype reconstruction from population data. Am. J. Hum. Genet. 68, 978-989 (2001).

15 Pierzchalska, M., Szabo, Z., Sanak, M., Soja, J. \& Szczeklik, A. Deficient prostaglandin E2 production by bronchial fibroblasts of asthmatic patients, with special reference to aspirin-induced asthma. J. Allergy Clin. Immunol. 111, 1041-1048 (2003).

16 Choi, J. H., Park, H. S., Oh, H. B., Lee, J. H., Suh, Y. J., Park, C. S. et al. Leukotrienerelated gene polymorphisms in ASA-intolerant asthma: an association with a haplotype of 5-lipoxygenase. Hum. Genet. 114, 337-344 (2004).

17 Farooque, S. P. \& Lee, T. H. Aspirin-sensitive respiratory disease. Annu. Rev. Physiol. 71, 465-487 (2009).

18 Shi, J., Misso, N. L., Duffy, D. L., Bradley, B., Beard, R., Thompson, P. J. et al. Cyclooxygenase-1 gene polymorphisms in patients with different asthma phenotypes and atopy. Eur. Respir. J. 26, 249-256 (2005). 
19 Akbari, O., Faul, J. L., Hoyte, E. G., Berry, G. J., Wahlstrom, J., Kronenberg, M. et al. CD4+ invariant T-cell-receptor+ natural killer T cells in bronchial asthma. N. Engl. J. Med. 354, 1117-1129 (2006).

20 Gromme, M. \& Neefjes, J. Antigen degradation or presentation by MHC class I molecules via classical and non-classical pathways. Mol. Immunol. 39, 181-202 (2002)

21 Kim, K. R., Cho, S. H., Choi, S. J., Jeong, J. H., Lee, S. H., Park, C. W. et al. TAP1 and TAP2 gene polymorphisms in Korean patients with allergic rhinitis. J. Korean Med. Sci. 22, 825-831 (2007).

22 Ramos, P. S., Langefeld, C. D., Bera, L. A., Gaffney, P. M., Noble, J. A. \& Moser, K. L. Variation in the ATP-binding cassette transporter 2 gene is a separate risk factor for systemic lupus erythematosus within the MHC. Genes Immun. 10, 350-355 (2009).

23 Yan, G., Shi, L. \& Faustman, D. Novel splicing of the human MHC-encoded peptide transporter confers unique properties. J. Immunol. 162, 852-859 (1999).

24 Momburg, F., Armandola, E. A., Post, M. \& Hammerling, G. J. Residues in TAP2 peptide transporters controlling substrate specificity. J. Immunol. 156, 1756-1763 (1996).
25 Choi, J. H., Lee, K. W., Oh, H. B., Lee, K. J., Suh, Y. J., Park, C. S. et al. HLA association in aspirin-intolerant asthma: DPB1*0301 as a strong marker in a Korean population. J. Allergy Clin. Immunol. 113, 562-564 (2004).

26 Sanak, M., Simon, H. U. \& Szczeklik, A. Leukotriene C4 synthase promoter polymorphism and risk of aspirin-induced asthma. Lancet 350, 1599-1600 (1997).

27 Van Sambeek, R., Stevenson, D. D., Baldasaro, M., Lam, B. K., Zhao, J., Yoshida, S. et al. $5^{\prime}$ flanking region polymorphism of the gene encoding leukotriene $\mathrm{C} 4$ synthase does not correlate with the aspirin-intolerant asthma phenotype in the United States. J. Allergy Clin. Immunol. 106, 72-76 (2000).

28 Keicho, N., Tokunaga, K., Nakata, K., Taguchi, Y., Azuma, A., Tanabe, K. et al. Contribution of TAP genes to genetic predisposition for diffuse panbronchiolitis. Tissue Antigens 53, 366-373 (1999).

29 Adair-Kirk, T. L., Atkinson, J. J. \& Senior, R. M. Smoke particulates stress lung cells. Nat. Med. 14, 1024-1025 (2008).

30 Malhotra, D., Thimmulappa, R., Vij, N., Navas-Acien, A., Sussan, T., Merali, S. et al. Heightened endoplasmic reticulum stress in the lungs of patients with chronic obstructive pulmonary disease: the role of Nrf2-regulated proteasomal activity. Am. J. Respir. Crit. Care Med. 180, 1196-1207 (2009).

Supplementary Information accompanies the paper on Journal of Human Genetics website (http://www.nature.com/jhg) 